\title{
OBSERVATIONS ON HAEMOLYTIC DISEASE OF THE NEWBORN*
}

\author{
BY \\ RONALD R. GORDON, M.C., M.B., Ch.B. \\ (From the Wards and Pathology Department, Royal Hospital for Sick Children, \\ Glasgow)
}

This article deals briefly with three aspects of haemolytic disease of the newborn which are of special interest. The first is the family history, with special reference to the occurrence of stillbirths and abortions in previous pregnancies; the second is the correlation of clinical and serological findings; and the third is the mortality rate. The observations recorded are based on 119 cases of icterus gravis neonatorum which were admitted to the Royal Hospital for Sick Children, Glasgow, from January, 1934, to April, 1946. The one case of hydrops foetalis, and the twenty-five cases of congenital haemolytic anaemia which were also admitted during this period, are not included.

\section{Family History}

It has been known for many years that icterus gravis neonatorum is a familial disease. The fact that a previous child suffered from jaundice shortly after birth is of importance in the differential diagnosis of any case of neonatal jaundice. With the discovery of the Rhesus factor and the mechanism by which the disease can be produced, the exact reason for this has become apparent. It has been suggested that the antibodies in the maternal serum can be held responsible for abortions and stillbirths as well as for affected children. If this is so, a history of abortions and stillbirths would rank in importance with that of a previously jaundiced child. In an attempt to discover the value of such a history, the obstetric histories of the mothers has been analysed (table 1).

TABLE 1

THE INCIDENCE OF ABORTIONS AND STILLBIRTHS IN 112 AFFECTED FAMILIES

\begin{tabular}{c|c|c|c}
\hline Pregnancies & Abortions & Stillbirths & Live births \\
\cline { 1 - 3 } 463 & 15 & 28 & 428 \\
\hline
\end{tabular}

$$
\begin{aligned}
& \text { abortion rate }=\frac{\text { abortions }}{\text { pregnancies }} \times 100=3.2 \text { per cent. } \\
& \text { stillbirth rate }=\frac{\text { stillbirths }}{\text { live births }} \times 100=6.5 \text { per cent. }
\end{aligned}
$$

\footnotetext{
* Communicated to the Annual Meeting of the British Paediatric
} Association at Rugby, on Aug. 3, 1946.
Of the 119 cases, seven were siblings of infants already included, so that only 112 families are represented. In these families there were recorded 463 pregnancies. Fifteen of these ended in abortion before the seventh month of gestation, twenty-eight ended in stillbirth (either premature or full term) and eight resulted in twins. There were, therefore, 428 live births.

The abortion rate, which is defined as the percentage of pregnancies ending in abortion, is, in this series, $3 \cdot 2$ per cent. Since abortions do not have to be registered there are no national figures for their incidence, but obstetric textbooks (Eden and Holland, 1937; Munro Kerr et al., 1933) quote figures as high as $\mathbf{2 0}$ per cent. of all pregnancies. In any event, 3 per cent. cannot be considered above the average and it would appear that abortions are not more common in families where one infant has had icterus gravis than they are in the general population.

The stillbirth rate is the proportion of stillbirths to live births expressed as a percentage. In this series the figure is 6.5 per cent. Stillbirths are registrable and, in 1943, the incidence in Glasgow was 3.6 per cent. (Report of Medical Officer of Health, 1943.) The stillbirth rate is, therefore, almost double the average in families where there has been an infant suffering from icterus gravis. It would appear, therefore, that a history of previous stillbirths is of some importance in indicating maternal sensitization to the Rhesus factor, but that a history of previous abortions is of none.

\section{Clinical and Serological Findings}

The second point to be considered is the correlation of clinical and serological findings. It is usually found that the mother is $\mathrm{Rh}$-negative, the infant Rh-positive, and that the mother's serum contains anti-Rh agglutinins. In some cases where the clinical findings are not typical, the serological findings may be of considerable help. Thus, recently, two infants have been seen, both thought to be examples of severe physiological icterus since in neither did blood examination reveal signs of haemolysis nor was there any splenomegaly, hepatomegaly, or bile in the urine. In both cases, however, the mother was found to be Rh-negative and her serum contained anti-R $\mathrm{h}$ agglutinins active 
against the child's red cells. The infants were kept under observation; they became anaemic, with splenomegaly and erythroblastaemia, and recovered after transfusion. It is, therefore, of importance to have the $R h$ testing done in all cases of jaundice occurring within the first few days of life. Indeed, if all mothers could have their blood tested during the last months of pregnancy it would be a step towards anticipating the occurrence of the disease.

When the mother and child are both Rh-positive, reconciliation with the clinical findings is more difficult. When the mother's serum contains agglutinins active against the infant's red cells it may be assumed, in most cases, that this is responsible for the disease. Most frequently this is due to an ABO group difference, but sometimes one of the rare anti$R h$ agglutinins may be found. It is known that the former may be associated with the disease, and if the anti-Rh agglutinins can pass through the placenta there seems no reason to doubt that the $x$ and $\beta$ agglutinins may also sometimes pass. The rare anti-Rh antibodies which may be present are anti$\mathbf{R h}^{\prime}$ (anti-C), anti-Rh" (anti-E) or anti-Hr' (anti-c). Only one anti-Hr" (anti-e) has been reported (Mourant, 1945), and the presence of anti-d has, so far, only been predicted (Race, 1944). When any of these are found, it is as conclusive serological evidence as finding anti-R $\mathrm{h}_{\text {。 }}$ (anti-D). It sometimes happens, however, that mother and child are both $\mathbf{R h}$-positive and there are no agglutinins in the maternal serum. Of the 112 families, fifty-two have so far reported for $R$ h-testing. Of these, forty-nine had the standard incompatibility of mother $\mathrm{Rh}$ negative and child or father (or both) $\mathrm{Rh}$-positive. In thirty-six of these the mother had anti-Rh agglutinins in her serum: in the thirteen in whom they were not found it was more than two years since the birth of an affected child.

In the three families where mother and child were both $\mathrm{Rh}$-positive there were no agglutinins in the maternal serum. Although in all three it was also some time since the birth of an affected child, there was something in the clinical history of each which raised the question of the accuracy of the diagnosis. In all three of the infants there were some of the typical findings of the disease, namely jaundice, anaemia, reticulocytosis, splenomegaly, hepatomegaly, and biluria. It was on the presence of these that the diagnosis was made.

The first child, however, was the result of a first pregnancy; the jaundice was not noticed by the parents until the fifteenth day, and both before and after admission to hospital there had been considerable melaena. On admission there was haematuria, and the reticulocyte count was only 1 per cent., although this rose later without further apparent haemorrhage. The spleen was never palpable in this case, but the haemoglobin level fell to 50 per cent., and there was bile and a considerable amount of pus in the urine. The child eventually recovered but is now hopelessly mentally deficient. There have been no further pregnancies in the family.

The second child was the result of a third preg- nancy, the first two having ended in abortion at the third month. The first abnormality noticed by the parents was a suprasternal swelling, apparently a haematoma although there were no other haemorrhages. The child became jaundiced and pale on the third day; liver and spleen both became enlarged but the urine did not contain bile. The haemoglobin was 52 per cent. and there was erythroblastaemia. This child recovered but, later, developed a haemarthrosis of his knee when two years old and finally died at the age of four years from a subarachnoid haemorrhage. Two further children born to this family were perfectly normal and both Rh-positive.

The third child was the thirteenth in the family; none of the others had been affected. He became jaundiced at two days and had two convulsions before his admission on the fourth day. His spleen was enlarged to four fingers' breadth below the costal margin, and his haemoglobin was $\mathbf{4 5}$ per cent. The reticulocyte count was 10 per cent., and there was no erythroblastaemia. This child recovered after transfusion and is well. This last case fitted more closely into the clinical picture than the other two, but maternal antibodies were only looked for on one occasion.

From study of the first two cases, the impression is gained that there are other conditions which may simulate the disease entity of icterus gravis. For example, the following case showed many of the features of the disease but was found at autopsy not to be affected.

The infant was apparently quite normal at birth; he was the second child in the family. He remained well until aged five weeks when he became jaundiced and drowsy. When admitted at seven weeks of age he had an enlarged liver and spleen, a haemoglobin of 104 per cent., and no reticulocytosis. Bile was present in the motions, and a gross pyuria was discovered. The pyuria and the jaundice cleared, and, as this occurred, the child became pale and his haemoglobin fell to 65 per cent. At the same time the reticulocytes rose to 12 per cent., although there was no increase in the number of nucleated red cells in the blood films. If the age of the child be excluded the picture is very similar to icterus gravis of fairly mild degree but the mother, father, and both children were all $R$ h-negative and the mother had no agglutinins to the others' red cells nor to any other of known Rh type. This child died, and at necropsy a healing pyelonephritis was the only abnormality found. To what extent the pyelonephritis was responsible for the other findings it is difficult to say, but it is interesting that the first of the three infants already described also had pyuria which was discovered two days after the haemoglobin had fallen suddenly from 90 to 50 per cent.

Boorman, Dodd, and Mollison (1944) found only three out of one hundred mothers of affected children to be Rh-positive. In two of these there was an incompatible $\mathrm{ABO}$ grouping with the child's cells; in the third there was present what is now known as the anti-E antibody. The earlier papers on the 
subject (Levine, 1941) gave 10 per cent. as the incidence of Rh-positive mothers, but the findings in the series recorded in the present communication appear to agree with the more recent figures.

\section{Mortality Rate}

The mortality rate for his own, and Rolleston's (1920), cases was given by Hampson (1929) as 80 per cent. With the introduction of blood transfusion in the treatment of the disease the mortality dropped appreciably (table 2 ). When Rh-negative blood was introduced, great hopes were entertained that practically all affected children could be saved. The original papers published seemed very encouraging (Gimson, 1943; Mollison, 1943), but Mollison, when commenting on seventeen recoveries out of seventeen transfused cases, gave warning that such figures might not always be expected since many of the transfused cases were only mildly affected. That such has proved to be correct is seen from table 2 .

TABLE 2

MORTALITY RATE IN ICTERUS GRAVIS NEONATORUM

\begin{tabular}{|c|c|c|}
\hline & Before Rh & After $R h$ \\
\hline $\begin{array}{l}\text { A. In } 119 \text { cases treated and } \\
\text { untreated: } \\
\text { Number of cases } \\
\text { Number of deaths } \\
\text { Mortality rate (per } \\
\text { cent.) } \\
\text { B. In } 105 \text { transfused cases: } \\
\text { Number of cases } \\
\text { Number of deaths } \\
\text { Mortality rate (per } \\
\text { cent.) }\end{array}$ & $\begin{array}{l}70 \\
43 \\
61 \cdot 4\end{array}$ & $\begin{array}{l}49 \\
16 \\
32 \cdot 7\end{array}$ \\
\hline
\end{tabular}

Of the 119 cases, seventy occurred before the introduction of $\mathrm{Rh}$-negative blood and forty-nine afterwards. Of the seventy cases occurring before, forty-three died-a mortality rate of 61.4 per cent. Of the forty-nine occurring after, sixteen died-a mortality rate of 32.7 per cent. However, since an attempt is being made to determine the value of transfusion therapy, the nine cases before, and five after, who died before transfusion could be given, must be excluded. When the transfused cases only are considered, the mortality rate is seen to have dropped from 55.7 to 25 per cent. (table 2) With the introduction of Rh-negative blood, therefore, the mortality rate has been more than halved. That progress has been made is undoubted, but that one in four of the treated cases has died is nevertheless disquieting. All the infants received at least one transfusion, and they did not die as a direct result of anaemia. That liver dysfunction plays a part seems now clear (Parsons, 1946) and is emphasized by the fact that of the twenty-five cases of congenital haemolytic anaemia admitted during the same period only two died, both of them before the use of Rh-negative blood. There have been no deaths in that condi- tion since. In congenital haemolytic anaemia there is usually evidence of greater blood destruction than in icterus gravis, and it is the obstructive type of jaundice present in the latter which is the cause of the much higher mortality. Wiener (1946) considers that the two conditions are caused by different antibodies, an agglutinin causing icterus gravis and a glutinin (blocking antibody) causing haemolytic anaemia. The former, according to his theory, is the one responsible for the liver damage and the latter causes only destruction of red cells. If this is so, one would expect from the variety of the clinical findings in many cases that both antibodies would be present. There are few cases of icterus gravis which. if they recover, do not become anaemic, and most cases of congenital haemolytic anaemia have some jaundice in the early stages of the disease. Unfortunately the blocking antibody can only be demonstrated in the presence of the agglutinin by a difference in titre, so that the presence of both cannot often be shown. Whether Wiener's serological classification of the disease will be confirmed and accepted remains to be seen (Lancet, 1946) but from the clinical point of view there are two extremes of the disease, as seen in a children's hospital. At one end severe jaundice with little anaemia, and at the other severe anaemia with little or no jaundice. The majority of cases, however, seem to fall between the two extremes. It has been suggested that transfusion as soon as possible after the diagnosis has been made, either on clinical or serological grounds, may improve the prognosis. In view of the part which liver dysfunction appears to play, there seems no valid reason for thinking that $R h$-negative cells or plasma will have a very beneficial effect on the prognosis unless anaemia is also present. It may. of course, have some effect in diminishing the haemorrhagic tendency which is often present, but that would not appear to be sufficient reason for its routine use unless the blood picture also indicates that transfusion is necessary. Terminal infection, mainly bronchopneumonia. was found in nine out of the eleven infants who died (table 2). Although these children are not premature by weight, their resistance to infection is low, as would be expected from their disordered metabolism, and this factor should be considered during their treatment.

The discovery of the Rhesus factor has certainly contributed greatly to the knowledge of serologists and geneticists, but the greatest advances so far have been on the purely scientific side. Broman (1945) has pointed out that nothing more than transfusion with $\mathrm{Rh}$-negative blood has been introduced for the benefit of the child. Caesarean section before term does not appear to have met with the success hoped for, and the prevention by other means of this disease, which is unique in its etiology, still seems remote.

\section{Summary}

1. In the differential diagnosis of haemolytic disease of the newborn, a history of previous stillbirths is of some importance in indicating maternal 
sensitization to the Rhesus factor, but a history of previous abortions is of none.

2. Other conditions may simulate the disease entity of icterus gravis neonatorum. Brief histories of three cases have been presented.

3. Since the introduction of transfusion with $R h$ negative blood, the mortality rate in all cases of icterus gravis neonatorum has fallen from 61.4 to 32.7 per cent., and in cases receiving one or more transfusions from 55.7 to 25 per cent.

4. The fact that the mortality is still so appreciable is due to the hepatic dysfunction which is present in the more severe forms of the disease.

I wish to thank Prof. D. F. Cappell for much valuable advice and the gift of sera. Dr. Stanley Graham, in whose wards the study has been made, has been a constant source of encouragement, and Dr. G. L. Montgomery has given me all possible help in his pathology department. Many of the cases were in Prof. G. B. Fleming's wards and I wish to thank him for allowing me to have access to their records and for continued interest.

\section{REFERENCES}

Boorman, K. E., Dodd, B. E., and Mollison, P. L. (1944). J. Obst. Gynaec. Brit. Emp., 51, 1.

Broman, B. (1945). Acta Paediat., 34, 158.

Eden, T. W., and Holland, E. (1937). A Manual of Obstetrics. 8th ed., London, 210.

Gimson, J. D. (1943). Brit. med. J., 2, 293.

Hampson, A. C. (1929). Lancet, 1, 429.

Lancet (1946). (Annotation.) 2, 242.

Levine, P. (1941). Amer. J. clin. Path., 11, 898.

Mollison, P. L. (1943). Proc. rov. Soc. Med., 36, 221.

Mourant, A. E. (1945). Nature, 155, 542.

Munro Kerr, J. M., et al. (1933). Combined Textbook of Obstetrics and Gynaecology. 2nd ed., Edinburgh, 225.

Parsons, L. G. (1946). J. Obst. Gynaec. Brit. Emp., 53, 1. Race, R. R. (1944). Nature, 153, 771.

Report of Medical Officer of Health, City of Glasgow. (1943). p. 12.

Rolleston, H. D. (1920). Practitioner, 104, 1.

Wiener, A. S. (1946). Amer. J. Dis. Child., 71, 14. 